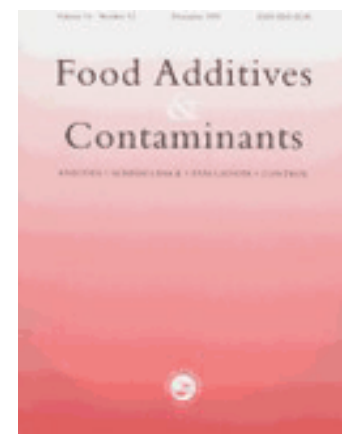

\title{
Gynaecomastia linked to the intake of a herbal supplement fortified with diethylstilbestrol
}

\begin{tabular}{|r|l|}
\hline Journal: & Food Additives and Contaminants \\
\hline Manuscript ID: & TFAC-2009-430.R1 \\
\hline Manuscript Type: & Original Research Paper \\
\hline Author: & 27-Jan-2010 \\
\hline Complete List of Authors: & $\begin{array}{l}\text { Toorians, Arno; St. Anna Zorggroep } \\
\text { Bovee, Toine; RIKILT-Institute of Food Safety, WUR, Safety and } \\
\text { Health } \\
\text { De Rooy, Janneke; St. Anna Zorggroep } \\
\text { Stolker, Linda; RIKILT-Institute of Food Safety, WUR, Residue and } \\
\text { Contaminant Analysis } \\
\text { Hoogenboom, Ron; RIKILT-Institute of Food Safety, Safety and } \\
\text { Health }\end{array}$ \\
\hline Methods/Techniques: & Bioassay, Chromatography - LC/MS, Clinical study, Toxicology \\
\hline Additives/Contaminants: & Drug residues - hormones, Hormones \\
\hline Food Types: & Nutritional supplements, Dietary supplements \\
\hline & \\
\hline
\end{tabular}

\section{SCHOLARONE \\ Manuscripts}




\title{
Gynaecomastia linked to the intake of a herbal supplement fortified with diethylstilbestrol
}

\author{
Arno W.F.T. Toorians ${ }^{1}$, Toine F.H. Bovee ${ }^{2^{*}}$, Janneke de Rooy ${ }^{1}$, Linda A.A.M. Stolker ${ }^{2}$, \\ Ron L.A.P. Hoogenboom² \\ ${ }^{1}$ St. Anna Zorggroep, P.O. Box 90, 5660 AB Geldrop, The Netherlands. \\ 2 RIKILT-Institute of Food Safety, Wageningen University and Research Centre, \\ Department of Safety \& Health, P.O. Box 230, 6700 AE Wageningen, The \\ Netherlands.
}

* Corresponding author: Tel.: +31-317480391, fax: +317-417717, e-mail: toine.bovee@wur.nl

Keywords: gynaecomastia, bioassay, diethylstilbestrol, prostate, supplements 


\begin{abstract}
This study reports the findings of a supplement marketed on the internet for prostate problems. The supplement was orally taken by a 60-year old man with divergent hormonal levels and who was surgically treated for gynaecomastia: development of abnormally large mammary glands in males. The supplement showed a strong effect in a yeast estrogen bioassay, expressing a yeast enhanced green fluorescent protein (yEGFP) upon exposure to estrogens. Using both NMR and a gradient liquid chromatographic time of flight mass spectrometric (LC/TOFMS) method, the response was shown to be caused by very high levels of diethylstilbestrol, known for causing gynaecomastia. The gynaecomastia was most probably caused by this orally taken 'natural' herbal supplement, as the patient hormonal levels also returned to normal again when stopping the use of it. This case demonstrates that physicians need to be aware of the use of supplements with illegal components that may be responsible for unwanted side-effects.
\end{abstract}




\section{Introduction}

Supplements for treatment of a variety of diseases can be easily obtained, without prescription by physicians, from various shops and through the internet. This is allowed since these products are based on natural compounds and do not contain pharmaceuticals. Pharmaceutical agents on the other hand can only be obtained through prescription by a physician. However, the use of supplements is not without risk, as shown by the following case, dealing with a vital 60-year old man who had undergone surgery for treatment of bilateral gynaecomastia.

Gynaecomastia is the development of abnormally large mammary glands in males and results in an enlargement of the male breast. Estrogens stimulate growth of breast tissue, androgens inhibit it. When the ratio between estrogens and androgens increases, breast tissue is stimulated to grow. Gynaecomastia is a common finding in the male population (Braunstein 2007). Three peaks in the age distribution can be identified: in neonates, in adolescent boys and in elderly. In neonates, the cases are due to the transfer of maternal estrogens and progesterone. Young men and adolescent boys are particularly sensitive to estrogens, while in the elderly gynaecomastia is associated with low testosterone levels. However, many cases of gynaecomastia have no clear cause, but about 10 to $20 \%$ are caused by drugs (Rohrich et al. 2003) for which over 300 pharmacological agents can be considered. Examples include the well known side effects of medications like cimetidine, ketocanazole, and spironolactone, but also medications specifically used to treat prostate cancer: cyproterone and flutamide, and even certain antipsychotics (Ismail and Barth 2001).

Here we report our findings with a patient who was treated for gynaecomastia. The case report describes a 60-year old man who was referred by a surgeon to evaluate 
the cause of bilateral gynaecomastia. His medical history did not reveal any abnormalities. The patient considered himself to be in a good physical condition, doing exercises on a weekly basis and he reported normal libido and erectile function. He had never used anabolic steroids, did not smoke and alcohol consumption was moderate. On physical examination this man was remarkably vital. His virilisation and body composition appeared normal (BMI of $26.6 \mathrm{~kg} / \mathrm{m}^{2}$ ). Examination of the chest and abdomen were normal. He had bilateral circumareolar scars. Andrologic examination revealed normal testes and epididymes. However, hormonal levels of sex steroids indicated hypogonadotropic hypogonadism (table 1). While discussing these findings with the patient, it became apparent that his prostate specific antigen (PSA) level had been evaluated on a regular basis. This had been established and further examined by an urologist, but there had been no complaints related to prostate hypertrophy or lower urinary tract symptoms. The family history revealed a father and a grandfather with prostate carcinoma. The urologist performed transrectal ultrasound guided prostate biopsies. These had been documented four and three years earlier and revealed normal prostate tissue. Despite these findings, the patient remained worried about his mildly elevated levels of PSA, remained afraid of possibly developing prostate cancer, and perceived regular transrectal biopsies as very stressful. Therefore he was not willing to agree with the proposed approach to repeat them on a regular basis. To find a solution, the patient had consulted a physician in a private practice to look for alternative treatments. This physician advised the use of a herbal supplement, labelled 'Prostasol', with the purpose to decrease the elevated PSA level and reduce the chance of developing prostate cancer. For approximately two years, the patient used the supplement with confidence, since his level of PSA became suppressed. However, in this period the 
patient had consulted a surgeon for his cosmetically bothersome gynaecomastia and was surgically treated. Hereafter the surgeon referred the patient to an internist, in order to find an explanation for the gynaecomastia.

In this study the patient was asked to stop the use of the supplement and his hormonal levels of sex steroids were examined again three and six months after stopping the use, as it was speculated that the observed effects were caused by this orally taken 'natural' herbal supplement. In particular, we studied the possibility that this 'natural' herbal supplement might contain steroids, using a combination of bioassays and confirmation techniques. The orally taken supplement was therefore screened in a yeast estrogen bioassay and the presence of an estrogenic substance was confirmed by NMR and LC/TOFMS analysis.

\section{Materials and Methods}

\section{Chemicals}

Diethylstilbestrol (DES) was obtained from ICN, 17 $\beta$-estradiol (E2) from Sigma, 17 $\beta$ testosterone (T) from Steraloids and dimethyl sulfoxide (DMSO) from Merck. Chemicals to prepare the growth media and the preparation of the growth media for yeast cells were as described elsewhere (Bovee et al. 2004). Two batches of the supplement were obtained from the patient, who had ordered them from the internet, in a package labelled 'Prostasol' and containing capsules with $450 \mathrm{mg}$. The first batch carried the charge number 050926 and was valid until 25-09-2008 and the second batch carried the charge number 070328 and was valid until 27-03-2010. The package was identical to those shown on the internet. The patient was advised by a physician to buy the supplement through the internet. According to the label, Prostasol contains beta-sitosterol, cellulose, serenoa repens, quercetin, pygeum, 
scutellaria baicalensis, magnesium stearate, potassium hydrogen phosphate, camposterol, stimgasterol, brassicasterol, ganoderma lucidum, panax pseudoginseng, colloidal silicium dioxide, urtica dioica, and zingiber officinale. A third batch was obtained from the internet and contained tablets of $910 \mathrm{mg}$. This third batch carried the charge number 080118 and was valid until 17-01-2011. Compared to the capsules, the tablets contained similar ingredients, but scutellaria baicalensis, urtica dioica, and zingiber officinale were left out and 5 other ingredients were included: triglycerides, resveravine (8\% resveratrol extract), sodium starch glycolate, hypromellose, and propylene glycol.

\section{Blood analysis}

Analysis of luteinizing hormone $(\mathrm{LH})$, follicle stimulating hormone $(\mathrm{FSH})$, prolactin and thyroid stimulating hormone (TSH) were performed by an immunoenzymatic assay, free thyroid hormone (FT4), testosterone (T) and estradiol (E2) were performed by a competitive immunoassay, all conform the procedure of the manufacturer (Beckman Coulter). Sex hormone binding globulin (SHBG), prostate specific antigen (PSA), human chorionic gonadotropin and alpha-fetoprotein were performed by a chemo-luminescence immunoassay conform the procedure of the manufacturer (Siemens). Free Testosterone was estimated according to the equation as described by Vermeulen et al. in 1999.

Yeast estrogen and androgen bioassays

A capsule of the supplement was opened and $100 \mathrm{mg}$ of the powder was extracted as described previously for feed (Bovee et al. 2006). The tablet was powdered and treated in the same way. In short, $100 \mathrm{mg}$ Prostasol was mixed with $4 \mathrm{ml}$ methanol and $4 \mathrm{ml}$ sodium acetate buffer $(0.25 \mathrm{~N}, \mathrm{pH} 4.8)$. The sample was incubated for 10 min in an ultrasonic bath and subsequently mixed head over head for 15 min, 
centrifuged at $3500 \mathrm{~g}$, and $4 \mathrm{ml}$ of the upper liquid phase was transfered to a glass tube. Next, the $\mathrm{pH}$ was adjusted to 4.8 using $4 \mathrm{~N}$ acetic acid and the extract was subjected to solid phase extraction (SPE) on a C18 column, previously conditioned with $2.5 \mathrm{ml}$ methanol and $2.5 \mathrm{ml}$ sodium acetate $\mathrm{pH} 4.8$. Subsequently, this column was washed with $1.5 \mathrm{ml} 10 \%(\mathrm{w} / \mathrm{v})$ sodium carbonate solution, $3.0 \mathrm{ml}$ water, $1.5 \mathrm{ml}$ sodium acetate $\mathrm{pH} 4.8,3.0 \mathrm{ml}$ water and finally with $2 \mathrm{ml}$ methanol/water $(50 / 50 \mathrm{v} / \mathrm{v})$. The column was air-dried and eluted with $4 \mathrm{ml}$ acetonitrile. The eluate was applied to an $\mathrm{NH} 2$-column that was previously conditioned with $3.0 \mathrm{ml}$ acetonitrile. The acetonitrile eluate thus obtained was evaporated to $3 \mathrm{ml}$ under a stream of nitrogen gas. A $200 \mu \mathrm{l}$ aliquot of this extract, equivalent to $3.3 \mathrm{mg}$ of the supplement, and several dilutions in acetonitrile were transferred to a 96 well plate in triplicate and 50 $\mu \mathrm{l}$ of a $4 \%$ DMSO solution in water was added to each well. To remove the acetonitrile, the plate was dried overnight in a fume cupboard and was then ready to be screened on estrogenic activity with the yeast estrogen bioassay. In the same way a reagent blank was prepared.

Cultures of the yeast estrogen and androgen biosensor were grown overnight at $30^{\circ} \mathrm{C}$ with vigorous orbital shaking. At the late log phase, the cultures of both cytosensors were diluted in the selective minimal medium supplemented with Lleucine $(\mathrm{MM} / \mathrm{L})$ to an optical density $(\mathrm{OD})$ value at $630 \mathrm{~nm}$ was reached between 0.04 and 0.06 . For exposure, aliquots of $200 \mu$ of this diluted yeast culture were pipetted into each well of a 96 -well plate and $2 \mu$ of a stock solution in DMSO was added to test the agonistic properties of the compounds. To test for anti-androgenic properties, $1 \mu \mathrm{l}$ amounts of the stock solutions were co-exposed with $1 \mu \mathrm{l}$ of $17 \beta$-testosterone stock solutions known to cause either a half-maximal or a near maximal response. DMSO and control containing only $17 \beta$-estradiol (E2) or $17 \beta$-testosterone (T) were 
included in each experiment and each sample concentration was assayed in triplicate. Exposure was performed for $24 \mathrm{~h}$ at $30^{\circ} \mathrm{C}$ and orbital shaking with $125 \mathrm{rpm}$. Fluorescence and OD were measured at 0 and $24 \mathrm{~h}$ directly in a SynergyTM HT Multi-Detection Microplate Reader (BioTek Instruments Inc., USA) using excitation at $485 \mathrm{~nm}$ and emission at $530 \mathrm{~nm}$. The fluorescent signal was corrected with the signals obtained with the supplemented MM containing DMSO solvent only. In order to check whether a sample was toxic for the yeast cells, densities of the yeast culture were determined by measuring the OD at $630 \mathrm{~nm}$.

NMR analysis

The methodology for sample preparation, analysis and measurement is described elsewhere (Lommen et al. 2002). Basically, a few mg's of the contents of the capsule were extracted with $1 \mathrm{ml}$ methanol-d4. In addition, ca. $1 \mathrm{mg}$ of the reference standard diethylstilbestrol was dissolved in $1 \mathrm{ml}$ methanol-d4 (Merck 99.8\%). The $1 \mathrm{H} \mathrm{NMR}$ analysis was performed on a Bruker AMX 400 WB spectrometer. Presaturation was performed on the HDO resonance. A $90^{\circ}$ pulse was used; the total relaxation delay was $3.7 \mathrm{~s}$; spectral width was $5000 \mathrm{~Hz}$. The data were acquired in $16 \mathrm{~K}$ data points at $300 \mathrm{~K}$. Before Fourier transformation and phasing, a 1/3 shifted quadrate sine bell filter was applied and a zero-filling to $128 \mathrm{~K}$. Calibration of spectra was achieved by setting the HCD2-resonance of deuterated methanol to $3.27 \mathrm{ppm}$.

\section{LC/TOFMS analysis}

A capsule of the supplement was opened and $10 \mathrm{mg}$ of the powder was transferred to a vessel and $10 \mathrm{ml}$ methanol was added. The tablet was powdered and treated in the same way. After ultrasonic treatment for $30 \mathrm{~min}, 25 \mu \mathrm{l}$ of the extraction solvent and $950 \mu \mathrm{L}$ of an internal standard DES-d6 in ethanol were transferred to a $2 \mathrm{ml}$ autosampler vial. This extract, containing DES-d6 (100 ng/ml), was analysed in 
duplicate on a high resolution UPLC/TOFMS. Separation was carried out with an ultra performance liquid chromatographic (UPLC ${ }^{T M}$ ) system, consisting of a vacuum degasser, autosampler, and a binary pump (Acquity UPLC system, Waters, Milford, MA, USA) equipped with a reversed phase Waters Acquity UPLC BEH C18 analytical column (50x2.1 mm, $1.7 \mu \mathrm{m}$ particle size). The gradient (solvent $A$, water-acetonitrile (90:10, v/v); solvent B, water-acetonitrile (10:90, v/v)) was: 0-2 min 25\% B; $2-15$ min linear increase to $90 \% \mathrm{~B}$ with a final hold for $1 \mathrm{~min}$. The injection volume was $10 \mu \mathrm{l}$ and the flow rate was $0.2 \mathrm{ml} / \mathrm{min}$. The UPLC system was connected to a Time-ofFlight Mass Spectrometer Waters-Micromass LCT Premier ToF equipped with an electrospray interface operating in the negative ion mode, using the following parameters: cone voltage $50 \mathrm{~V}$, capillary voltage $2700 \mathrm{~V}$, source temperature $120^{\circ} \mathrm{C}$, and desolvation temperature $350^{\circ} \mathrm{C}$. Full scan spectra from 100 to $1000 \mathrm{Da}$ were acquired with a scan time of $0.25 \mathrm{~s}$. Mass accuracy was maintained by using a lock spray with lock mass of leucine-enkefaline 12C [M-H] ion m/z 556.2771. Resolution was at least $10,000 \mathrm{FWHM}$ at $\mathrm{m} / \mathrm{z}$ of the lock mass. Dynamic range enhancement (DRE) was switched on.

For quantification, a detector response versus concentration plot was constructed with six different concentrations of DES in methanol $(0-250 \mathrm{ng} / \mathrm{ml}$ and DES-d6 at 100 $\mathrm{ng} / \mathrm{ml}$ ) by plotting the ratio of the peak area of the extracted ion chromatogram (EIC) for DES m/z 267.1385 (mass of the $[\mathrm{M}-\mathrm{H}]^{-}$ion) and the peak area of the EIC for DES$\mathrm{d} 6 \mathrm{~m} / \mathrm{z} 273.1761$ against the concentration. The concentrations in the samples were calculated using the linear regression method. 


\section{Results and Discussion}

Plasma hormone levels

When it became clear that the patient used a herbal supplement, which could be a possible factor in the cause of the hypogonadotropic hypogonadism and the development of gynaecomastia, he was asked to stop this use. His hormonal levels of sex steroids were examined again three and six months after stopping the use. As shown by the plasma hormone levels in table 1, the patient showed hypogonadotropic hypogonadism with a normal prolactin level while using the supplement. There were no signs or symptoms of bitemporal hemianopsia, no clinical signs of a Cushing syndrome, acromegaly nor hypothyroidism. There were neither signs of severe illness, stress or excessive exercise, which can also cause a reversible deficiency of gonadotropins. (McLeod and Iversen 2000). The patient showed decreased levels of LH and T and elevated levels of SHBG.

Hypothalamic gonodatrophin releasing hormone $(\mathrm{GnRH})$ regulates the production of the pituitary gonadotrophins, luteinizing hormone (LH) and follicle stimulating hormone $(\mathrm{FSH})$. LH acts primarily on the Leydig cell to stimulate testosterone synthesis. The regulatory control of androgen synthesis is mediated by testosterone and estrogen feedback on both the hypothalamus and pituitary. The majority of androgens, more than $90 \%$, are produced by the testes. Approximately $80 \%$ of estrogens are of extra-gonadal origin and originate from peripheral aromatisation of androgens. This is illustrated schematically in figure 1 (McLeod and Iversen 2000). Thus the patient's decreased level of LH was accompanied by a related suppressed level of testosterone.

However, the elevated level of SHBG was remarkable. Intravascular, the majority of the sex steroids are connected to SHBG, which has a higher affinity for androgens 
than for estrogens. Levels of SHBG increase with higher levels of estrogens and decrease with higher levels of androgens. As the patient's E2 level was normal and his $T$ levels were decreased, the increased SHBG level was surprisingly. It was therefore hypothesised that some ingredients of the herbal supplement might cause an estrogen-like effect on the hypothalamic-pituitary-testis-axis or might cause an inhibiting action on testosterone production. In that aspect, the patient's gynaecomastia could also be explained, as gynaecomastia develops in case of misbalance between hormones with estrogenic effects over hormones with androgenic effects. Such an increased estrogen-androgen ratio can be the result of increased levels of estrogens, decreased levels of androgens or increased levels of estrogen precursors. Moreover, gynaecomastia can develop in association with hypogonadotropic hypogonadism.

The patient was then asked to stop the use of the supplement and his hormonal levels, measured three and six months after stopping the intake of the supplement, supported the hypothesis, as his levels of $\mathrm{T}, \mathrm{LH}$, and $\mathrm{FSH}$ became normal again (table 1). Also, the SHBG level returned to normal and can be explained by the lower estrogen-androgen ratio, as androgens inhibit production of SHBG. However, the patient now clearly showed elevated E2 level, for which we have no explanation, and PSA level. It was concluded that if the hypothesis was right and the supplement is involved, it should contain a strong estrogenic compound. In addition, it might contain a supplementary compound with an anti-androgenic mode of action.

\section{Examination of the supplement}

According to the manufacturers' website, Prostasol contains the so-called herbal components saw palmetto, ginseng, skullcap, and reishi. These components are apparent in comparable products called 'SPES' and 'PC SPES'. Both SPES and PC 
SPES are described by their manufacturer as herbal mixtures for a non-estrogenic treatment for prostate cancer. However, the contents of SPES and PC SPES are sometimes questioned. The California State Department of Health Services issued a public health warning about SPES and PC SPES after they tested positive for the drugs alprazolam and warfarin respectively (sonic.net/ brianf/caoma/spes_recall_m.htm). Also the U.S. Food and Drug Administration (FDA) came up with a safety alert (www.fda.gov/medwatch/SAFETY/2002/safety02.htm). Regarding Prostasol, the website mentions that Prostasol contains quercetin, sitosterol, zinziber officinalis, urtica dioica, and pygeum (www.med-pro.org). This herbal food supplement is marketed as 'a non-estrogenic mixture' in the treatment for mild prostate cancer and is described by its manufacturer as a pharmaceutical that is tested on toxicity in a trial with prostate cancer patients. According to the manufacturer, these studies revealed that it has a positive effect on the quality of life as it helps against the pain due to disseminations in the bones with both patients with hormone sensitive and insensitive prostate cancer. Moreover, the website mentions that the PSA levels in more than $70 \%$ of the patients decreased. In a placebo controlled survey of 200 men with benign prostate hypertrophy examining the substance beta-sitosterol, a component of Prostasol, it was reported that there were no significant side effects of beta-sitosterol and it was suggested that beta-sitosterol is a safe agent (Berges et al. 1995). However, that study reports only self-reported urological variables and there are no endocrine data on levels of sex steroids and gonadotropins. Quercetin, another component of Prostasol blocks growth of androgen sensitive humane prostate cancer cells (Yuan et al. 2005). Quercetin inhibits expression of the human androgen receptor, playing a role in proliferation, differentiation and maintenance of function of 
the prostate. Finally, pygeum has been shown to diminish enzyme activity of 5 alphareductase and to have inhibiting effects on inflammation (Breza et al. 1998). There is one published study that showed a suppression of testosterone upon intake of Prostasol and that effect was allocated to the presence of phytoestrogens (Clement and Bubley 2008). However, Prostasols' contents were not thoroughly analysed in that study. Because it is questionable whether the information on the label about the contents of the supplement is reliable, it was decided to further investigate the androgenic and estrogenic characteristics of this herbal mixture. Bioassays are an ideal tool for tackling this kind of problems since they are also able to detect previously unknown hormonal compounds. The different batches of the supplement were therefore screened for estrogenic activity in a yeast estrogen bioassay. Figure 2 shows the responses obtained with several dilutions of an extract prepared from the first batch. It clearly shows that the supplement contains at least one strong estrogenic compound. The extract had to be diluted at least a 10.000 times in order to obtain a signal lower than the maximum response in this bioassay. Based on the E2 standard curve, it was estimated that this first batch contained about $0.3 \mathrm{mg}$ "E2 equivalents" per gram.

For identification of the estrogenic compound(s), we decided to first analyse a sample by NMR as the amount seemed to be in de mg per gram range. This revealed the possible presence of diethylstilbestrol (DES). With the aid of a DES standard, the identity was confirmed, as all 4 multiplet signals of DES could be found in the extract at the correct positions (data not shown). Identification and confirmation of DES was then performed by LC/TOFMS analysis. Figure 3 shows the ion current chromatograms of mass $267.1357 \pm 0.0001 \mathrm{Da}$ of a standard solution of DES (250 ng per $\mathrm{ml})(3 \mathrm{~A})$ and the methanol extract that was prepared from the same Prostasol 
batch (3B). Figure $3 \mathrm{C}$ shows the ESI-TOF mass-spectrum taken at the retention time of DES. It confirms the presence of DES in the extract. The calculated amount from a duplo analysis for this capsule was $0.9 \pm 0.2 \mathrm{mg}$ DES per gram.

A capsule of a second batch, also obtained from the patient, was analysed and revealed the presence of an estrogenic activity corresponding to $3.6 \mathrm{mg}$ "E2 equivalents" per gram in the bioassay and $4.1 \pm 0.1 \mathrm{mg}$ DES per gram by LC/TOFMS analysis. DES has been shown to be about as potent as E2 in the yeast estrogen assay (Bovee et al. 2004). This means that the semi-quantitative calculated amounts from the bioassay should more or less be comparable with the amounts determined by LC/TOFMS analysis. The results from both batches show that this is indeed the case. After the patient was informed a new batch of Prostasol was ordered from the internet and contained tablets instead of capsules. When analysed in the same way, the tablets contained no estrogenic activity and no DES.

As NMR analysis did not reveal the presence of any other steroids in the first two batches, we tested whether the anti-androgenic effects, as observed in the patient, could also be due to DES. We therefore tested DES in the yeast androgen bioassay by testing DES with and without the addition of $17 \beta$-testosterone $(\mathrm{T})$. In this way we were previously able to demonstrate the specific anti-androgenic action of compounds such as flutamide, but also the known anti-androgenic properties of E2 and 17 $\alpha$-ethinylestradiol (Bovee et al. 2008 and Bovee et al. 2009). These results are shown in figure 4 and clearly demonstrated that DES can also act as an androgen receptor antagonist.

The patient was advised to take 4 capsules of Prostasol per day, corresponding to about $4.5 \mathrm{mg}$ DES per day. As DES is about as estrogenic as E2 and $17 \alpha-$ ethinylestradiol and as an average birth control pill contains about $0.03 \mathrm{mg} 17 \alpha$ - 
ethinylestradiol per tablet, it means that this patient was orally taking an estrogenic amount that is equal to 150 birth control pills per day. Moreover, compared to $17 \alpha-$ ethinylestradiol, DES is regarded as a less save agent. In 1971, in utero exposure was found to be associated with a greatly increased risk of clear cell carcinoma of the vagina and cervix, known world wide as the DES daughters (Herbst et al. 1971). Subsequently, DES use was found to be associated with an increased risk of breast cancer in women who took the drug (Colton et al. 1993). The latest results suggest that the DES daughters also have an increased risk of breast cancer after age 40 years (Palmer et al. 2006). Even the fertility of men exposed to DES has been investigated, but revealed that there was no increased risk of infertility among men exposed to DES before birth (Wilcox et al. 1995). However, several studies have shown a misplaced opening of the penis (hypospadias), epididymal cysts (noncancerous groths on the testicle), and undescended testicles (cryptorchidism) (Wilcox et al. 1995 and Brouwers et al. 2006). In addition, DES has been studied in the treatment of prostate carcinoma, but high doses of DES, $5 \mathrm{mg}$ per day, were associated with increased mortality from cardiovascular disease. With a $1 \mathrm{mg}$ per day dose there was no increase in cardiovascular mortality, but it appeared to be as effective as the high dose, although the testosterone level was not completely suppressed (Brawer 2001 and Montgomery et al. 2007).

The adulteration of natural supplements with synthetic compounds is not new. Katz et al. (2002) mentioned about the related supplement PC-SPEC that 'at present, a more extensive controversy surrounds this herbal agent because (unpublished, but highly publicized) analyses suggest that some batches were contaminated with synthetic hormone (DES) and/or blood coagulation effector (warfarin). If true, it is certainly another indicator of a need for more rigorous regulation of the nutraceutical industry'. 
PC-SPES, a herbal additive comparable to Prostasol, is no longer allowed in the US since 2002, as it was also shown to contain traces of warfarin. Oh et al. (2004) had to terminate a clinical trial comparing PC-SPES with DES when it turned out that the supplement contained variable amounts of DES. Sang et al. (2006) described the presence of ethinylestradiol in batches of PC-SPES. With regard to Prostasol, the Danish Medicines Agency in November 2006 issued a warning that it may contain diethylstilbestrol and encouraged people to stop using it and hand over the remaining part of the product to a pharmacy (www.dkma.dk/1024/visUKLSArtikel.asp?artikellD=10577).

\section{Conclusions}

An elevated estrogen-androgen ratio in a 60-year old male patient probably caused the development of gynaecomastia, for which he was surgically treated. As demonstrated by the decreased levels of $\mathrm{T}$ and $\mathrm{LH}$, there was hypogonadotropic hypogonadism. This patient was using a herbal supplement. It was hypothesised that some ingredients of this supplement might have caused an estrogen-like effect on the hypothalamic-pituitary-testis-axis or an inhibiting action on testosterone production. In particular the increased SHGB level led to this idea. When the patient stopped the use of the supplement, his T, SHGB, FSH, and $\mathrm{LH}$ reversed to normal levels.

Since Prostasol contains some natural ingredients that might lead to estrogenic and anti-androgenic effects in vivo, we investigated whether these natural compounds could have had the strength to cause the observed gynaecomastia. Using a yeast estrogen bioassay, it was shown that the supplement used by the patient, caused a very high estrogenic activity, corresponding to $\mathrm{mg}$ amounts of E2 equivalents per 
gram of supplement. NMR and LC/TOFMS analysis subsequently showed that this 'natural' product contained huge amounts of the synthetic estrogen DES. When tested in the yeast androgen bioassay, it was shown that DES can also inhibit the response of testosterone. These results show that DES can act both as a strong estrogen receptor agonist and a strong androgen receptor antagonist. The presence of this huge amount of the synthetic drug DES in the supplement is incontrovertible related to the observed abnormal hormonal levels in this patient as all these abnormalities can be explained by the activities of DES. Moreover, DES is orally active and has previously been shown to cause gynaecomastia (Wortsman et al. 1989 and Malkowicz 2002).

At this stage we are not able to explain the increased level of estradiol as observed after stopping the use of the supplement. After stopping, the patient also showed an increased PSA level again, but lowering the PSA level to reassure a patient is a questionable advice.

In summary, as lower urinary tract symptoms in an increasing number of men threaten their quality of life, they are stimulated to use health improving products, but it is a misconception to think that so called natural medications, herbal drugs or food additives cannot cause side effects. Moreover, this case shows that these products might contain ingredients that are not mentioned on the label. Although highly publicized, it is hardly published and the main of consumers are probably not familiar with all the issues involved. This in combination with insufficient communication between physicians and patients can result in potentially dangerous interactions (Capodice and Katz 2006). In our case it led to an unnecessary removal of breast tissue. 


\section{References}

Berges RR, Windeler J, Trampisch HJ, Senge T. 1995. Randomised, placebocontrolled, double-blind clinical trial of beta-sitosterol in patients with benign prostatic hyperplasia. Beta-sitosterol Study Group. The Lancet. 345:1529-1532.

Bovee TFH, Helsdingen JR, Rietjens IMCM, Keijer J, Hoogenboom LAP. 2004. Rapid yeast estrogen bioassays stably expressing human estrogen receptors $\alpha$ and $\beta$, and green fluorescent protein: a comparison of different compounds with both receptor types. Journal of Steroid Biochemistry and Molecular Biology. 91:99109.

Bovee TFH, Bor G, Heskamp HH, Hoogenboom LAP, Nielen MWF. 2006. Validation and application of a robust yeast estrogen bioassay for the screening of estrogenic activity in animal feed. Food Additives and Contaminants. 23:556568.

Bovee TFH, Schoonen WGEJ, Hamers ARM, Jorge Bento M, Peijnenburg AACM. 2008. Screening of synthetic and plant-derived compounds for (anti)estrogenic and (anti)androgenic activities. Analytical and Bioanalytical Chemistry. 390:1111-1119.

Braunstein GD. 2007. Gynecomastia. New England Journal of Medicine. 357:12291237.

Brawer MK. 2001. The evolution of hormonal therapy for prostatic carcinoma. Rev Urol. 3(3):1-9.

Breza J, Dzurny O, Borowka A, Hanus T, Petrik R, Blane G, et al. 1998. Efficacy and acceptability of tadenan (Pygeum africanum extract) in the treatment of benign prostatic hyperplasia (BPH): a multicentre trial in central Europe. Curr Med Res Opin. 14:127-139. 
Brouwers MM, Feitz WFJ, Roelofs LAJ, Kiemeney LALM, Gier RPE, Roeleveld N. 2006. Hypospadias: a transgenerational effect of diethylstilbestrol? Human Repruduction. 21:666-669.

Capodice JL, Katz AE. 2006. What patients take without telling you: holistic approach for BPH (review). World Journal of Urology. 24:378-382.

Clement J, Bubley G. 2008. Prostasol and venous thromboembolism. Urology. 72(3):664-666.

Colton T, Greenberg ER, Noller K, et al. 1993. Breast cancer in mothers prescribed diethylstilbestrol in pregnancy. J Am Med Assoc. 269:2096-2100.

Herbst AL, Ulfelder H, Poskanzer DC. 1971. Adenocarcinoma of the vagina: association of maternal stilbestrol therapy with tumor appearance in Young women. N Engl J Med. 284:878-881.

Ismail AA, Barth JH. 2001. Endocrinology of gynaecomastia. Annals of Clinical Biochemistry. 38:596-607.

Katz AE. 2002. PC-SPES: Herbal formulation for prostate cancer - Editorial comment 2. Urology. 60:377-377.

Lommen A, Schilt R, Weseman J, Roos AH, Van Velde JW, Nielen MWF. 2002. Application of 1D 1H NMR for fast non-targeted screening and compositional analysis of steroid cocktails and veterinary drug formulations administered to livestock. J Pharm Biomed Anal. 28:87-96.

Malkowicz B. 2002. The role of diethylstilbestrol in the treatment of prostate cancer. Urology. 58:108-113.

McLeod DG, Iversen P. 2000. Gynecomastia in patients with prostate cancer: a review of treatment options. Urology. 56:713-720. 
Montgomery RB, Nelson PS, Lin D, Ryan CW, Garzotto M, Beer TM. 2007. Diethylstilbestrol and docetaxel: a Phase II study of tubulin active agents in patients with metastatic, androgen-independent prostate cancer. Cancer. 110:996-1002.

Oh WK, Kantoff PW, Weinberg V, Jones G, Rini BI, Derynck MK, Bok R, Smith MR, Bubley GJ, Rosen RT, DiPaola RS, Small EJ. 2004. Prospective, multicenter, randomized phase II trial of the herbal supplement, PC-SPES, and diethylstilbestrol in patients with androgen-independent prostate cancer. Journal of Clinical Oncology. 22:3705-3712.

Palmer JR, Wise LA, Hatch EE, Troisi R, Titus-Ernstoff L, Strohsnitter W, Kaufman R, Herbst AL, Noller KL, Hyer M, Hoover RN. 2006. Prenatal diethylstilbestrol exposure and risk of breast cancer. Cancer Epidemiol Biomarkers Prev. 15:1509-1514.

Rohrich RJ, Ha RY, Kenkel JM, Adams WP jr. 2003. Classification and management of gynecomastia: defining the role of ultrasound assisted liposuction. Plastic Reconstructive Surgery. 111:909-923.

Sang SM, Liu ZH, Rosen RT, Ho CT. 2006. Bioassay-guided isolation, identification, and quantification of the estrogen-like constituent from PCSPES. In: Herbs: Challenges in Chemistry and Biology, ACS Symposium Series 925; p.117-125.

Vermeulen A, Verdonck L, Kaufman JM. 1999. A critical evaluation of simple methods for the estimation of free testosterone in serum. Journal of Clinical Endocrinology and Metabolism. 843:666-3672.

Wilcox AJ, Baird DD, Weinberg CR, Hornsby PP, Herbst AL. 1995. Fertility in men exposed prenatally to diethylstilbestrol. New Engl J Med. 332:1411-6. 
Wortsman J, Hamidinia A, Winters SJ. 1989. Hypogonadism following long-term treatment with diethylstilbestrol. American Journal of the Medical Sciences. 297:365-368.

Yuan H, Gong A, Young CY. 2005. Involvement of transcription factor Sp1 in quercetin-mediated inhibitory effect on the androgen receptor in human prostate cancer cells. Carcinogenesis. 26:793-801. 
Table 1: Hormonal values of a 60 -year old patient who suffered from gynaecomastia.

\begin{tabular}{lcccc}
\hline Normal values & $\begin{array}{c}\text { During use of } \\
\text { 'Prostasol' }\end{array}$ & $\begin{array}{c}\text { 3 months after } \\
\text { stopping the use of } \\
\text { 'Prostasol' }\end{array}$ & $\begin{array}{c}6 \text { months after } \\
\text { stopping the use of } \\
\text { 'Prostasol' }\end{array}$ \\
\hline PSA & $<3.5 \mu \mathrm{g} / \mathrm{l}$ & 0.96 & 5.7 & 11.6 \\
\hline Estradiol & $40-120 \mathrm{pmol} / \mathrm{l}$ & 108 & 150 & 253 \\
\hline Testosterone & $9-38 \mathrm{nmol} / \mathrm{l}$ & 0.4 & 11.7 & 11.9 \\
\hline Free testosterone & $175-750 \mathrm{pmol} / \mathrm{l}$ & 3 & 260 & 288 \\
\hline LH & $2-15 \mathrm{U} / \mathrm{l}$ & 1.6 & 3.8 & 12.6 \\
\hline FSH & $2-10 \mathrm{U} / \mathrm{l}$ & 2.2 & 11.8 & 115 \\
\hline SHBG & $10-70 \mathrm{nmol} / \mathrm{l}$ & 127 & 126 & 1.7 \\
\hline Prolactin & $0-250 \mathrm{mU} / \mathrm{l}$ & 157 & 1.2 & 16.5 \\
\hline TSH & $0,3-5,2 \mathrm{mU} / \mathrm{l}$ & 1.7 & 16 & \\
\hline F-T4 & $12-28 \mathrm{pmol} / \mathrm{l}$ & 14.5 & & 22 \\
\hline Alpha foetoprotein & $0-15 \mu \mathrm{g} / \mathrm{l}$ & normal & normal & \\
\hline Beta HCG & $<5 \mathrm{U} / \mathrm{l}$ & &
\end{tabular}


Figure legends

Figure 1.

Glandularand extraglandular origins and interrelations of the androgens: testosterone, DHT, androstenedione, and the estrogens: estradiol and estrone, and their effect on breast tissue. The effect of prostate cancer treatments on these pathways is also shown. Thick arrows denote the major sources of the hormone (obtained from McLeod and Iversen 2000).

Figure 2.

Responses of E2 ( closed diamonds [nM]) and the first batch of Prostasol ( closed triangle $[\mu l])$ in the yeast estrogen bioassay expressing human estrogen receptor $\alpha$ and yeast enhanced green fluorescence protein upon exposure to estrogens.

Figure 3.

Accurate mass LC-TOFMS analysis of the first batch of Prostasol. A Standard solution DES (250 ng per ml). B Methanol extract of Prostasol. C The ESI-TOF massspectrum of the Prostasol extract taken at the retention time of DES.

Figure 4.

Responses of testosterone $(\mathrm{T})(+$ plus $)$, DES ( $\Delta$ open triangle) and DES in combination with a high ( $\boldsymbol{\Delta}$ closed triangle) and low ( $\boldsymbol{\nabla}$ closed triangle) dose of $\mathrm{T}$, in the yeast androgen bioassay expressing human androgen receptor and yeast enhanced green fluorescence protein upon exposure to androgens. 


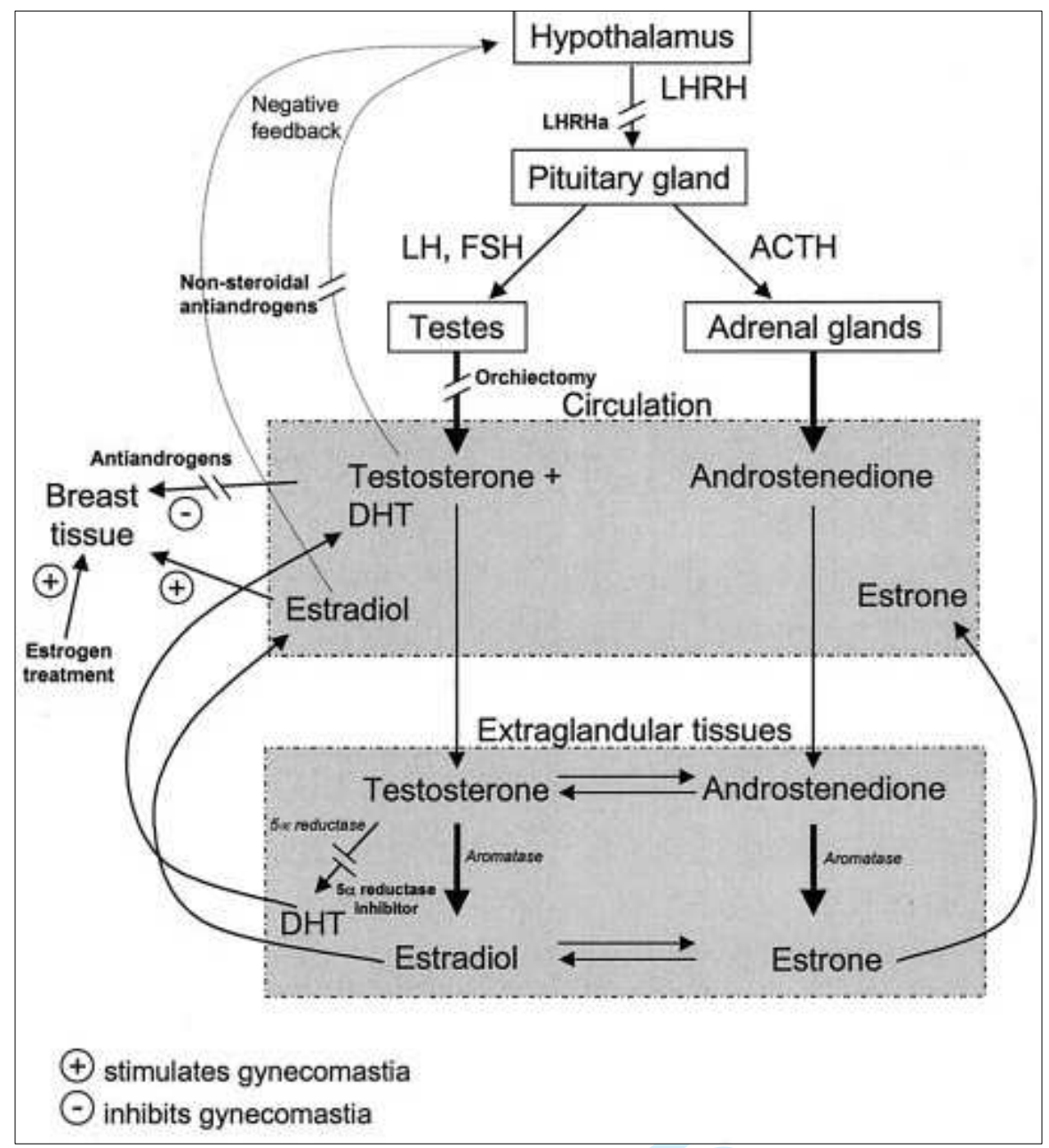


Responses of E2 ( $\bullet$ closed diamonds $[\mathrm{nM}]$ ) and the first batch of Prostasol ( $\boldsymbol{\Delta}$ closed triangle $[\mu \mathrm{l}]$ ) in the yeast estrogen bioassay expressing human estrogen receptor alpha and yeast enhanced green fluorescence protein upon exposure to estrogens. $270 \times 208 \mathrm{~mm}(120 \times 120 \mathrm{DPI})$ 
RIK0215677 MeOH extract (1.04 mg/ml)
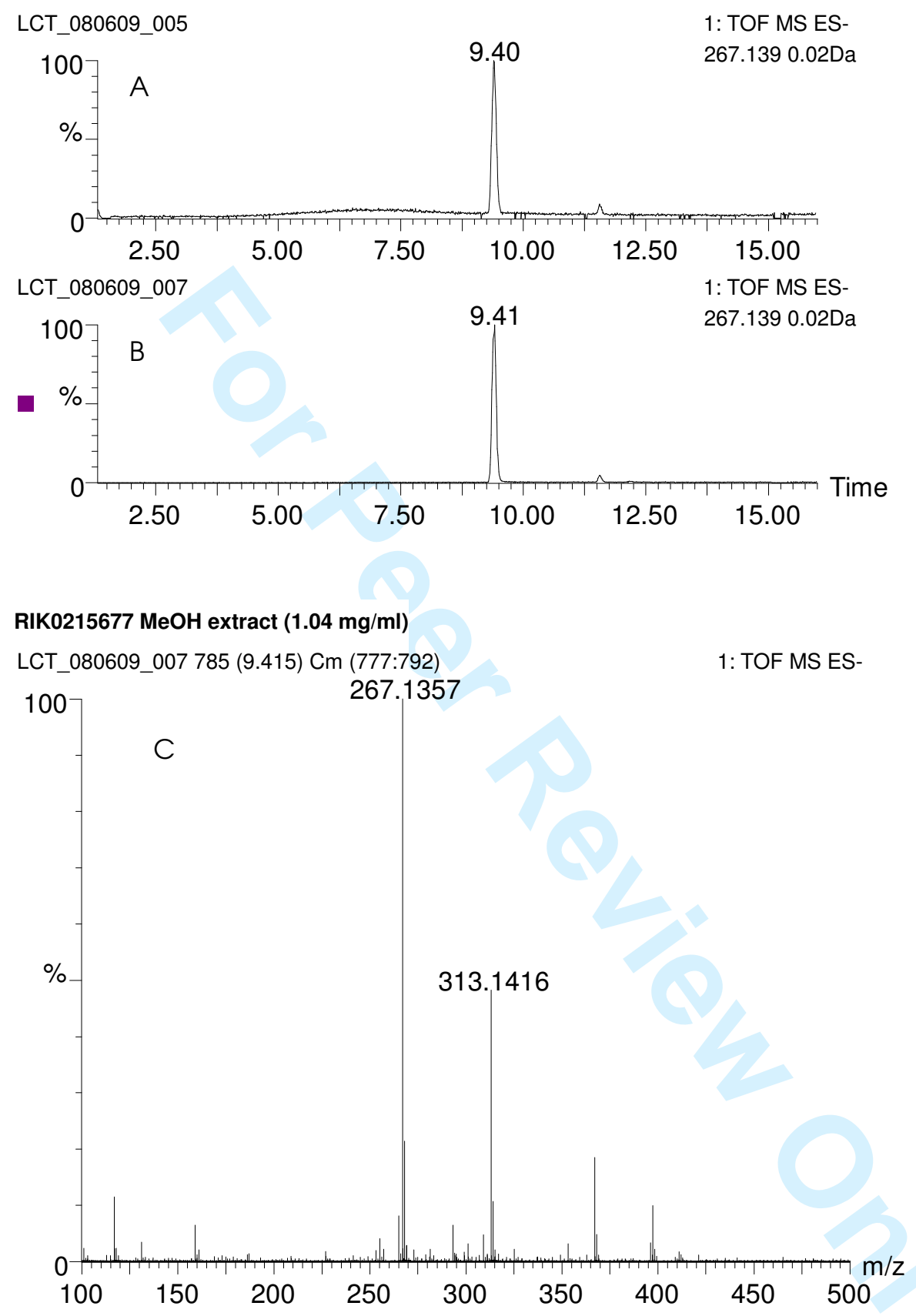
Responses of testosterone (T) ( + plus), DES ( $\Delta$ open triangle) and DES in combination with a high ( $\boldsymbol{\Delta}$ closed triangle) and low ( $\boldsymbol{\nabla}$ closed triangle) dose of $\mathrm{T}$, in the yeast androgen bioassay expressing human androgen receptor and yeast enhanced green fluorescence protein upon exposure to androgens. $270 \times 208 \mathrm{~mm}(120 \times 120 \mathrm{DPI})$ 